\title{
Two kinds of intracranial stimulation as counterconditioners of persisting avoidance in rats*
}

\author{
JAMES P. HUNSICKER, THOMAS C. NELSON, and LARRY D. REID \\ Bradley University, Peoria, Illinois 61606
}

\begin{abstract}
Rats were fixed with chronically indwelling electrodes to provide intracranial stimulation (ICS). ICS for one group stimulated the medial forebrain bundle and was positively reinforcing. ICS for another group stimulated subcortical areas away from the forebrain bundle and yielded forced movement and no reinforcement. After tests for effects of ICS, rats were trained to avoid footshock by climbing from a grid to a shelf that retracted periodically. After avoidance was established, footshock was terminated and rats were prevented from further responding by removal of the shelf. During three different periods of response prevention, the two kinds of ICS and no ICS were imposed, yielding nine treatments conforming to a 3 by 3 factorial design. After treatment, the shelf again was available and rats' perseveration of avoidance tabulated. Rats receiving positively reinforcing ICS during longer response prevention times responded the least.
\end{abstract}

Avoidance persists long after the initially maintaining aversive stimulus is discontinued (e.g., Solomon \& Wynne, 1953; Baum, 1970). Forcing rats to remain in circumstances that previously elicited active avoidance, thereby preventing opportunities to avoid (response prevention or flooding), has been shown to be effective in reducing avoidance over a relatively wide range of parametric variations (Baum, 1970). If affectively positive stimuli (stimuli when made contingent are positively reinforcing) are programmed during response prevention (counterconditioning), there is even more reduction of subsequent avoidance (Wilson \& Davidson, 1971; Reid, 1973).

The clearest demonstrations of the efficacy of counterconditioning have used positive hypothalamic intracranial stimulations (ICS) as counterconditioners (Gordon \& Baum, 1971; Reid, 1973; Reid, Taylor, \& Rassel, 1971). Positive hypothalamic ICS, however, is a complex stimulus that may elicit many responses, including positive affect, forced movement, and, when not contingent upon a particular response, active locomotion and exploratory behavior. Since it has been difficult to draw unequivocal conclusions about counterconditioning processes when conventional positive reinforcing stimuli have been used (Wilson \& Davidson, 1971; Reid, 1973), it seems strategic to attempt an understanding of the essential counterconditioning properties of hypothalamic ICS. Consequently, the counterconditioning efficiency of nonreinforcing ICS that elicited forced movement was compared to that of positive ICS and no ICS to segregate the effects of movement from the positive affective qualities of ICS.

*This study is part of a program of study and research directed by Larry Reid and Harold Miller and supported by funds of Bradley University's Board of Research, which administers NSF: Grant CUU 3320.

\section{METHOD}

\section{Subjects}

Ss were 36 adult male Sprague-Dawley rats. Twenty-eight were fixed in standard ways with chronically indwelling electrodes, the balance received sham operations. Electrodes were bipolar, stainless steel, and insulated except at the tips' cross section. Electrodes were aimed for two sites: the medial forebrain bundle of the lateral hypothalamus and the internal capsule-crus cerebri just lateral to the hypothalamus. Stimulation of the forebrain bundle produces positive reinforcement with a minimum of forced movement, whereas stimulation of the internal capsule-crus cerebri activates efferent fibers evoking gross movements. Rats were eventually segregated into no ICS, positive ICS, and movement ICS groups. Rats from each group were assigned randomly to three levels of response prevention, and consequently, there were nine experimental conditions, four rats under each.

\section{Apparatus}

ICS was $60-\mathrm{Hz}$ sine waves of $0.25-\mathrm{sec}$ duration with intensity determined for each rat, but always between 20 and $70 \mu \mathrm{A}$, peak to peak. Footshock was $1.3 \mathrm{~mA}$ and generated by a Grason-Stadler shock source and scrambler. Leads for ICS and the grid floor were never connected at the same time, preventing interaction between the two kinds of electrical stimulation.

Responsiveness to ICS was verified by tests in two chambers: a small box with a lever that yielded a single ICS when depressed and a modified shuttlebox (Valenstein \& Meyers, 1964). In the shuttlebox, ICS was delivered every $2 \mathrm{sec}$ when the rat was in one side of the chamber. The side of ICS changed periodically (mean about $47 \mathrm{sec}$ ), thereby forcing the rat to shuttle from side to side to either receive or avoid and escape ICS. If the rat neither approached nor escaped ICS, it would eventually receive $50 \%$ of possible ICS.

The avoidance apparatus was similar to one described in detail by Baum (1965). Briefly, it was a box with an electrifiable grid floor and a retractable shelf extending $6.4 \mathrm{~cm}$ through the width $(30.5 \mathrm{~cm})$ of one side of the square box, $15.2 \mathrm{~cm}$ above the floor. Weight of the rat closed a switch in the shelf.

\section{Procedure}

The procedure. with modifications to include extra groups. 


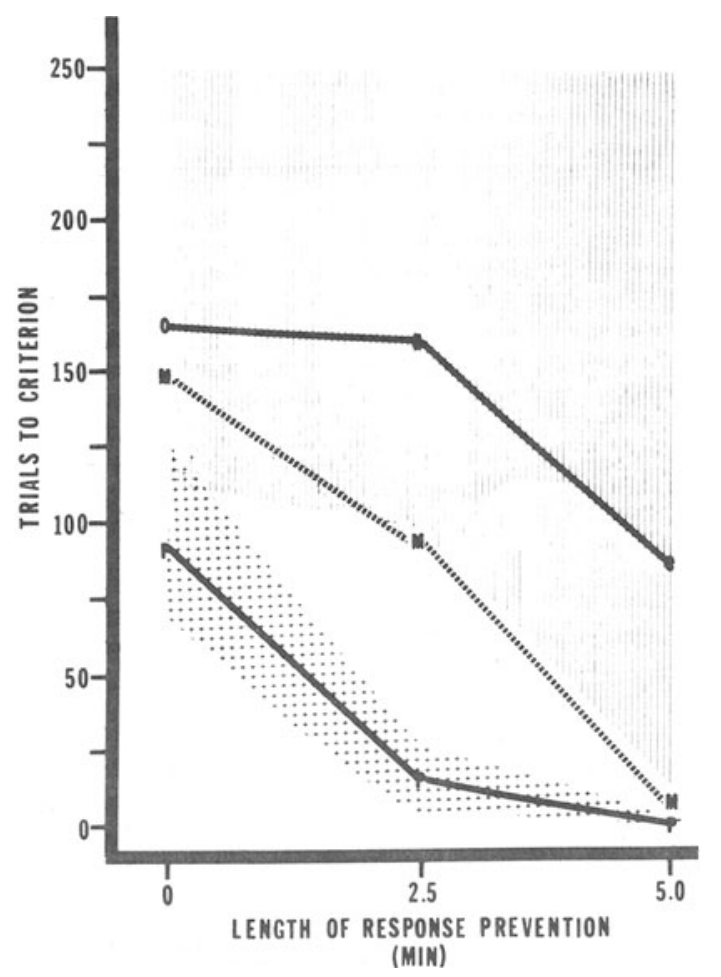

Fig. 1. Mean number of climbs to the shelf for each rat prior to meeting extinction criterion. Means designated by $P$ are of rats that received P-ICS, by $M$ of rats that received M-ICS, by 0 of rats that received no ICS. Along the abscissa are amounts of time rats spent on the grid while responding was prevented. The designated areas reflect ranges of performance for rats receiving P-ICS and 0-ICS.

was essentially the same as that used by Gordon and Baum (1971). After recovery from surgery, responsiveness to ICS was measured. Then each rat was trained to avoid, given one of nine treatments, and tested for the effects of its treatment in an extinction paradigm.

Each rat was placed in the levered box, and attempts were made to shape pressing for ICS as intensity of ICS was varied. With those rats that pressed, an intensity of ICS was selected that elicited the least forced movement and sustained the highest pressing rates. If a rat did not press initially, further attempts were made to shape pressing while intensity was varied, and eventually an intensity of ICS was selected that produced vigorous forced movement and no self-stimulation. The selected intensities from these tests were used throughout the balance of the experiment. Rats without electrodes and rats that failed to press were left in the box the same as were rats that eventually received ICS as a treatment.

To verify that appropriate assignment of Ss had been made, rats were tested in the shuttlebox. After familiarization with shuttlebox contingencies, there were three 5-min sessions, each separated by $12 \mathrm{~h}$, during which the number and maximum potential number of ICS were recorded. Rats designated to receive no ICS were also placed in the box.

To qualify as a member of the P-ICS group, a rat had to meet these standards: (a) it had to self-stimulate, averaging more than one press every $3 \mathrm{sec}$; (b) it had to approach ICS in the shuttlebox and get greater than $70 \%$ of the maximum possible ICS; and (c) it could show little or no forced movement in any of the tests. To qualify as a member of the M-ICS group, a rat had to (a) not self-stimulate, (b) neither approach nor avoid ICS in the shuttlebox and receive no less than $40 \%$ nor more than $60 \%$ of possible ICS, and (c) show marked movement with each ICS. The 0-ICS group met the standard of equivalent handling.

Within 1 or 2 days after tests with ICS, rats began avoidance training by being placed directly on the grid. After $10 \mathrm{sec}$, the grid electrified until the rat climbed to the shelf. After $30 \mathrm{sec}$ on the shelf, the shelf retracted, returning the rat to the grid and beginning a new trial. When the rat climbed to the shelf within $10 \mathrm{sec}$, it avoided footshock and was allowed $30 \mathrm{sec}$ on the shelf. If the rat fell or climbed from the shelf, the shelf retracted and a new trial began. This regimen continued until rats avoided 10 out of 10 times, which was usually accomplished in less than 20 trials.

After acquisition, footshock was terminated, and the shelf retracted for $5 \mathrm{~min}$. The rat was immediately picked up from the grid after the 10th avoidance, and electrode leads were connected. Rats that received no ICS were handled as similarly as possible. If the rat was scheduled for zero response prevention, it was placed in a pail near the apparatus for $5 \mathrm{~min}$. If the rat was scheduled for $2.5 \mathrm{~min}$ of response prevention, it spent $2.5 \mathrm{~min}$ in the pail and then $2.5 \mathrm{~min}$ on the grid. Rats receiving $5-\mathrm{min}$ response prevention spent $5.0 \mathrm{~min}$ on the grid. Rats scheduled to receive ICS received their ICS throughout the 5 min either in the pail or on the grid, or both, depending upon their group membership. Intervals between ICS were $2 \mathrm{sec}$. When 5 min ended, rats were again picked up and their electrodes were disconnected; they were then placed upon the returned shelf to begin extinction tests. Thirty seconds later, if the rat did not climb down, the shelf retracted, beginning a series of trials that were terminated when the rat stayed on the grid for 5 consecutive minutes or for an accumulated 250 trials. The sounds of the scrambler continued during testing for perseveration of responding the same as it had during training.

\section{RESULTS}

Statistical analyses indicated no systematic differences or biases among groups at the time of treatment, allowing analyses of posttreatment scores without consideration of differences in pretreatment performance. The three measures of posttreatment performance, trials to extinction criterion, number of "avoidance" to criterion, i.e., number of climbs to shelf in less than $10 \mathrm{sec}$, and time to first climb to shelf after treatment, were analyzed separately. Results were summarized by an analysis of variance for a 3 by 3 factorial design, with factors being variety of ICS presentation (none, ICS that produced movement, and positively reinforcing ICS) and amount of response prevention $(0,2.5$, and $5.0 \mathrm{~min})$. All three analyses indicated that the two factors of ICS presentation and response prevention time were reliable sources of variance, but for only one measure (time of first response) was the interaction reliable. $F$ values for trials to criterion, perhaps the most meaningful measure, were $10.3,10.9$, and 0.9 for ICS factor, response prevention factor, and their interaction, with $2 / 27,2 / 27$, and $4 / 27 \mathrm{df}$, respectively, yielding $\mathrm{p}$ values for the two main effects that were less than .001 .

Rats receiving no ICS and zero response prevention can be thought of as a no-treatment control group, and therefore their performance is a standard for comparison. Using the statistic suggested by Dunnett 
(Winer, 1962) for comparing all groups to a control, it was determined that only the treatments of P-ICS during 2.5 and $5.0 \mathrm{~min}$ of response prevention and M-ICS during $5.0 \mathrm{~min}$ of response prevention met statistical standards $(\mathrm{p}<.05)$, indicating reliable differences. These three groups met the standard for the measures of trials and "avoidance" to criterion, but only the group with P-ICS during 5-min response prevention met the standard on time to first response.

All summaries of data (see Fig. 1) indicate that P-ICS during response prevention produced marked reduction in responding compared to other treatments. To show more completely the difference between P-ICS and M-ICS as treatments, the following are the raw data for trials to extinction with $2.5-\mathrm{min}$ response prevention: Rats of P-ICS made 6, 8, 18, and 27 responses compared to rats of M-ICS, which made $17,76,136$, and 152 . The results of the histological verification of stimulation sites are depicted in Fig. 2.

\section{DISCUSSION}

Contained in this experiment is a direct replication of Gordon and Baum (1971). They compared P-ICS to no ICS at 0 and $5 \mathrm{~min}$ of response prevention. These results are remarkably similar to their results in showing that P-ICS during 5-min response prevention produced dramatically less responding. Furthermore, in previous work (Reid, 1973; Reid, Taylor, \& Rassel, 1971), it was shown that P-ICS efficiently attenuated persisting avoidance in a signaled leverpressing paradigm. Hence, across laboratories and Es, in different paradigms and in the same paradigm, lateral hypothalamic P-ICS has been shown to be effective in producing rapid extinction of active avoidance when that ICS is delivered during response prevention.

M-ICS during $5 \mathrm{~min}$ of response prevention led to an attenuation of responding; a result that replicates, conceptually, Liederhandler and Baum's (1970) finding of attenuation of responding with forcing movement by pushing the rats with a paddle. However, forcing movement is inefficient compared to P-ICS as a counterconditioner in comparisons across Baum's experiments and this experiment.

Exploratory approach-like behavior may be an inextricable activity associated with P-ICS (Glickman \& Schiff, 1967), and it may not make much sense to try to segregate this type of movement from the positiveness of ICS. However, for elicited movement to be efficient as a counterconditioner, it must be correlated with positive affective responses. Baum and Gordon (1970) found a reasonable correlation between such activities as grooming and exploration (generically called relaxation by Baum, 1970) and responses to extinction, i.e., if rats "relaxed" during response prevention, they spent less time avoiding during subsequent testing. P-ICS forced responses similar to those indexed by Baum, particularly sniffing with forward movement. The imposition of

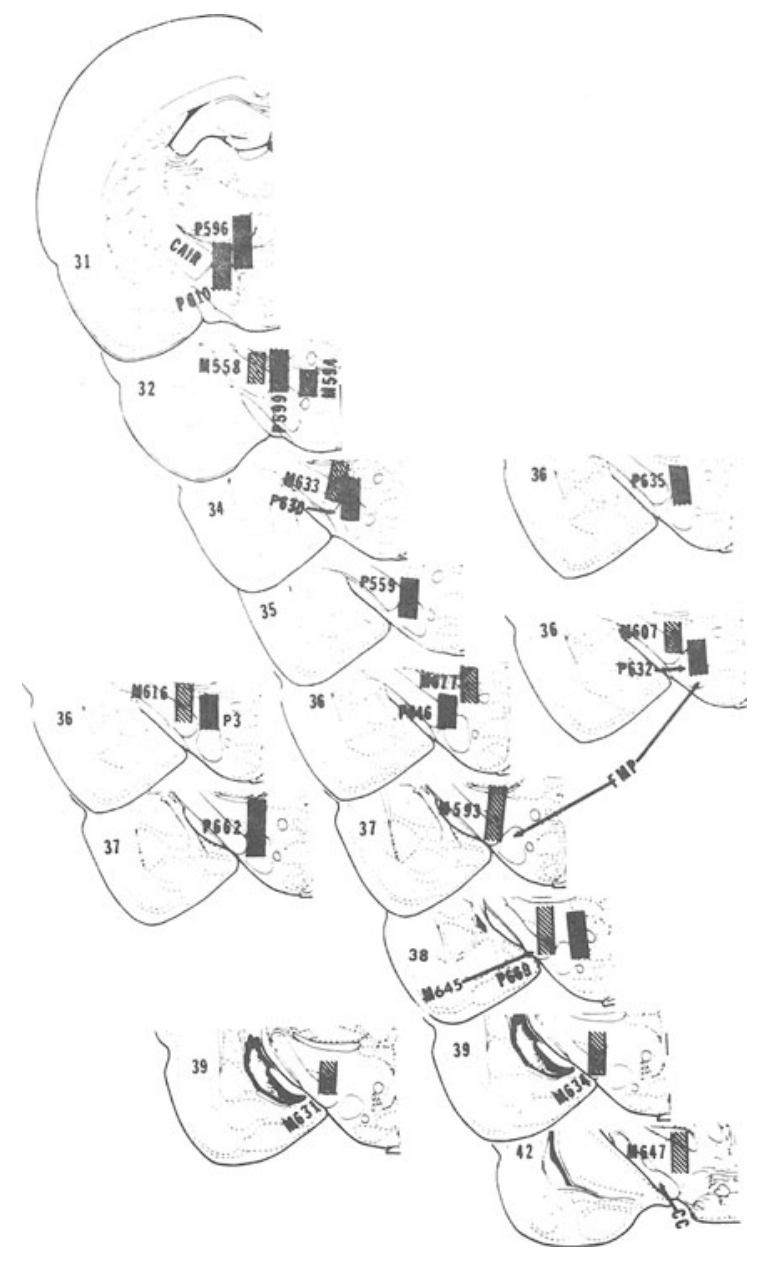

Fig. 2. Locations of electrode tips on plates from the atlas of König and Klippel (1963). Locations designated by $P$ and rat's number are of the P-ICS group; those designated by $M$ are of M-ICS. All rats' sites are shown except for one rat for whom we could not verify the exact site, but whose tip was probably near those depicted on Plate 32, and an M-ICS rat whose electrode was accidentally placed into the midbrain reticular formation.

"relaxation" during anxiety elicitation is counterconditioning, and it seems that ICS is an effective way to impose such "relaxation." We doubt that "relaxation" adequately describes the active state elicited by P-ICS.

These data combine with other data (Baum \& Gordon, 1970; Reid, 1973) to indicate that a strong stimulus programmed during response prevention is not efficient in hastening nonresponding. The idea that an efficient counterconditioner is one that merely distracts the $\mathrm{S}$ or merely provides an opportunity for response substitution is only weakly supported. Although there inevitably may be associative bonds established between the stimuli of response prevention and stimuli and responses programmed during response prevention, only certain stimuli or responses are truly efficacious in terms of counterconditioning. Only a theory of 
counterconditioning that stresses qualitative differences among potential counterconditioners is supported.

\section{REFERENCES}

Baum, M. An automated apparatus for avoidance training of rats. Psychological Reports, 1965, 16, 1205-1211.

Baum, M. Extinction of avoidance responding through response prevention (flooding) in rats. Psychological Bulletin, 1970, 74, 276-284.

Baum, M., \& Gordon, A. Effect of a loud buzzer applied during response prevention (flooding) in rats. Behavioral Research \& Therapy, 1970, 8, 287-292.

Glickman, S. W., \& Schiff, B. B. A biological theory of reinforcement. Psychological Review, 1967, 74, 81-109.

Gordon, A., \& Baum, M. Increased efficacy of flooding (response prevention) in rats through positive intracranial stimulation. Journal of Comparative \& Physiological Psychology, 1971, 75, 68-72.

König, J. F. R., \& Klippel, R. A. The rat brain. Baltimore: Williams \& Wilkins, 1963.

Liederhandler, I., \& Baum, M. Mechanical facilitation of the action of response prevention (flooding) in rats. Behavioral Research \& Therapy, 1970, 8, 43-48.

Reid, L. D. Processes of fear reduction in systematic desensitization: An addendum to Wilson \& Davison. Psychological Bulletin, 1973, 79, 107-109.

Reid, L. D., Taylor, C. L., \& Rassel, L. M. Efficient deconditioning of avoidance. Paper read at the Psychonomic Society meeting, St. Louis, Missouri, November 1971.

Solomon, R. L., \& Wynne, L. C. Traumatic avoidance learning: The outcome of several extinction procedures with dogs. Journal of Abnormal \& Social Psychology, 1953, 48, 291-302.

Valenstein, E. S., \& Meyers, W. J. Rate-independent test of reinforcing consequences of brain stimulation. Journal of Comparative \& Physiological Psychology, 1964, 57, 52-60.

Wilson, E. H., \& Davison, G. C. Processes of fear reduction in systematic desensitization: Animal studies. Psychological Bulletin, 1971, 76, 1-14.

Winer, B. Statistical principles in experimental design. New York: McGraw-Hill, 1962.

(Received for publication October 17, 1972; revision accepted March 27, 1973.) 